ISSN: 2162-3104 Print/ ISSN: 2166-3750 Online

Volume 6, Issue 1 (2016), pp. 262-282

(C) Journal of International Students

http://jistudents.org/

\title{
Factors that Contribute to the Adjustment of International Students
}

\author{
Jean Kesnold Mesidor \\ Florida State University College of Medicine (USA)
}

Kaye F. Sly

Jackson State University (USA)

\begin{abstract}
Leaving home to attend college is an important milestone for college students. However, the transition from home to college can be challenging, especially for students studying abroad. In this article, the authors explore factors that contribute to the academic, cultural, social, and psychological adjustments of international students. Adjustment issues include psychological distress such as homesick, depression, and anxiety. This article seeks to increase the reader's understanding of some of the issues faced by international students during the process of adjusting to a new collegiate environment. More specifically, the article discusses factors that contribute to adjustment and different phases of cultural adjustment. This article may help the students, educational institutions, and policy makers to provide the resources necessary for a seamless transition for international students to overcome the issues.
\end{abstract}

Keywords: International students, psychological adjustment, cultural adjustment, social adjustment, academic adjustment, cultural intelligence,

Leaving home to attend college is an important milestone for college students. However, the transition from home to college can be challenging, especially for students studying abroad. International college students are likely to experience adjustment issues when they enter college. Multiple factors contribute to the academic, social, cultural, and psychological adjustment of international students. Some international students find it easy 
to adjust to or cope with the stressors associated with living and studying in a foreign country, while others experience psychological distress. There is considerable research that documents how both personal and interpersonal factors impact the adjustment process of international students (Poyrazli \& Grahame, 2007; Smith \& Khawaja, 2011; Wang, Wei, Zhoa, Chuang, \& Li, 2015; Yi, Lin, \& Kishimoto, 2003; Zhang \& Goodson, 2011). This article will to increase the reader's understanding about some of the issues that international students face during the process of adjusting to a new collegiate environment. More specifically, the article discusses factors that contribute to adjustment and it discusses the different phases of cultural adjustment. The article concludes with recommendations for students, educators and policy makers about culturally sensitive activities that promote the smooth transition and/ or that facilitate the adjustment of the international student to the new environment.

\section{LITERATURE REVIEW}

The number of international students attending colleges and universities in the U.S. has increased significantly (Institute of International Education, Open Door, 2014). During the academic year of 2013-2014, there were 886,052 international students enrolled in US universities and colleges, which constituted an increase of $8.1 \%$. More specifically, the number of international students increased by $72 \%$ (514,723 to 886,052 students) from 2000 to 2014. Since the number of international students continues to increase, an understanding of the factors associated with their adjustment is critical.

Adjustment, derived from the Latin word ad-justare, is the process by which one balances needs and the obstacles in his or her environment. Yi et al. (2003) identified five areas in which international students are likely to experience adjustment issues. These areas included academic, physical health, financial, vocational and personal/social. Gebhard (2012) also studied international students' adjustment problems and behaviors. He found that students encountered problems in adjustment in three primary areas, academic, social interaction, and emotional reaction to their novel environment. Language barriers, unfamiliarity with available resources and how to access those resources, lack of an established social support system and/or social network compound the problems experienced in those areas (Smith \& Khawaja, 2011) and often manifest in depression, loneliness and isolation (Wei et al., 2007). Wang et al., (2015) used the term "crosscultural loss" to describe the process in which international students struggle to adjust to the loss of things familiar to them (e.g., personal relationships, home/country environment, and educational system) while trying to adjust 
to a new culture and environment. They found that cross cultural loss decreased with life satisfaction, positive affect, general self-efficacy and social connection with mainstream society, all of which are indicators of increased cultural adjustment or acculturation.

\section{Cultural Adjustment}

Trifonovitch (1977) identified four stages of cultural adjustment. Stage one is the honey moon stage, which is characterized by feelings of excitement. In this phase, students feel good about themselves and are ready to start their new adventure. They may feel a sense of accomplishment because they are studying in a foreign land. Their dreams have come true. Although the students may be thrilled about living in a new culture, the honey moon stage may also be characterized by discord because of cultural differences and misunderstandings. The second stage is the hostility stage. International students in the hostility stage can no longer tolerate the misunderstandings and misinterpretations experienced of the new culture. The students may experience culture shock which is expressed by feelings of frustration, anger, sadness, confusion, anxiety, and depression. Students in this stage are more likely to attribute their problems to external factors. They may also experience cultural mistrust, become uncooperative, unmotivated, and uninterested in pursuing their educational goals. The humor stage is characterized by the students' ability to engage in more relaxing activities such as laughing and socializing. Students reflect on the process issues that they faced during the hostility stage. They interact more with others because they have made friends and they have begun to enjoy their academic activities. The final stage is called the home stage. The home stage is characterized by the students feeling settled in the new environment or culture because they feel accepted. The students learn the norms and standards of the new culture and they integrate elements of their home culture into the new one. Cultural maladjustment is more likely to occur during the initial stages, honey moon and hostility, while cultural adjustment begins in the humor stage and completes during the home stage. Smith and Khawaja (2011) called the transition from maladjustment to cultural adjustment acculturation, or the process in which international students adjust their world view to fit or integrate with the mainstream culture in which they find themselves. They noted that acculturation is a complex, dynamic and multidimensional process. Some students successfully adjust and achieve cultural competence, while others experience acculturative stress.

An understanding of the two important concepts pertaining to adjustment: Cultural intelligence and emotional intelligence can further illustrate the cultural adjustment process. The concept of cultural 
intelligence can help us understand the adjustment that the international students undergo throughout their experience of living in a foreign land. Cultural intelligence refers to the ability of a person to interact, relate, adapt, and work effectively across cultures. A student may have a high intelligence quotient (IQ) however; this does not guarantee successful adjustment because he or she could have low cultural intelligence. Morrell, Ravlin, Ramsey, and Ward (2013) found that prior international experience was positively related to all dimensions of cultural intelligence. Cultural intelligence and psychological hardiness were found to be predictors of successful psychological adjustment of international students (Harrison \& Brower, 2011). The concept of psychological hardiness is sometimes used interchangeably with resilience.

The concept of emotional intelligence is related to cultural intelligence. Emotional intelligence is the ability to recognize, evaluate, manage ones' emotions, and interact with others. An emotionally intelligent student has the ability to sort out individual or group behavior and can adjust his or her behavior accordingly. An emotionally intelligent student also has the ability to understand human nature and understand individual differences. International students who are emotionally intelligent are more likely to successfully adapt to a new culture. Research supports the relationship between emotional intelligence and cultural adjustment. Jazaeri and Kumar (2008) found that emotional intelligence significantly predicted cultural adjustment. Similarly, Gullekson and Tucker (2012) investigated the relationship between emotional intelligence and intercultural growth among international students. They found that emotional intelligence predicted intercultural growth. Students who scored higher on the emotional intelligence measure reported higher level of intercultural growth in the short-term programs. International students scored significantly lower on emotional intelligence than did domestic students (Parker, Pettijohn, \& Rozell, 2011). Thus, it is important for international students to cultivate emotional intelligence. Rawlings and Sue (2013) encouraged educators to incorporate emotional intelligence into academic pedagogy in order to facilitate the international students' cultural adjustment.

\section{Social Adaptation}

Zhang and Goodson (2011) conducted a meta-analysis of sixty-four studies published in peer-reviewed journals between January 1990 and January 2009 that focused on predictors of psychosocial adjustment of both undergraduate and graduate international students. They found that stress, social support, English proficiency, region/country of origin, length of residence in the United States, acculturation, social interaction with Americans, self-efficacy, gender, and personality significantly predicted 
psychosocial adjustment. International students' tendency to gossip was a positive contributor to their sociocultural adaptation (Ji-yeon \& Pistole, 2014). A study conducted with Taiwanese international students found that their personality traits, knowledge of the United States, attitude about making friends with Americans and Taiwanese, their proficiency in English, and their social environmental context predicted the likelihood of the students forming friends with Americans 14 months after their arrival in the United States (Ying, 2002). Perceived social support was significantly related to the psychological adjustment of international college students (Mohd-Yusoff \& Othman, 2011).

Furthermore, international students were more likely to perceive greater socioemotional and instrumental support from other international people than from Americans (Chavajay, 2013). A positive relationship was found between social networking and social adjustment (Lin, Peng, Kim, Kim, \& LaRose, 2012). International college students who interacted with Americans and native friends through Facebook had better social adjustment. Internet use was found to significantly predict positive social and emotional adjustment among international students. Gómez, Urzúa, and Glass (2014) found that international students' acculturative process was positively associated with participation in leisure activities, such as sports, and social events. Participating in leisure activities and establishing a social network were significant predictors of social adjustment to college for international students. International college students became more acculturated and perceived fewer barriers to leisure as they became more engaged in leisure activities. Attending on-campus social events and networking were significantly important to social adjustment. Similarly, Baba and Hosoda (2014) found that social support partially mediated the relationship between stress factors and cross-cultural adjustment for international college students. Duru and Poyrazli (2011) investigated perceived discrimination, social connectedness, and other predictors of adjustment difficulties among Turkish international students. Those who reported having higher levels of social connectedness, lower levels of discrimination, more years of study in the U.S, and higher levels of English language proficiency reported lower levels of adjustment difficulties. Lack of social connectedness and perceived discrimination predicted adjustment difficulties.

\section{Academic Adjustment}

Most international students would agree that one of their optimal goals for pursuing education abroad is to gain an education that will allow them to make a difference in their lives and the lives of others. Education plays a transformative role as it fosters, in some sense, change and 
adaptation. The enthusiasm to learn guides the educational journey of international students. Learning to adjust to the new academic environment is the first learning experience of successful international students. Thus, it is not surprising that international students face many issues related to academic adjustment. Rienties, Beausaert, Grohnert, Niemantsverdriet, and Kommers (2012) found a negative correlation between social adjustment and academic performance. Lowinger, He, Lin, and Chang (2014) studied male and female Chinese students studying in the United States. They found that discrimination and homesickness was associated with academic procrastination for male Chinese students, while female Chinese students' academic procrastination was associated with academic self-efficacy, English language ability, culture shock and stress. A study conducted by Kuo (2011), found that international students faced language challenges in the area of listening comprehension and oral proficiency. Students were not able to understand the lectures presented in class. Academic, personalemotion and environmental factors were also significantly related to crosscultural adjustment.

Some students have to adjust to the educational system of the state and/or country in which they are studying. This process can be challenging and stressful. Though the students have some expectations about the university or college that they will attend, they may experience anxiety about registering for classes, or starting school. The process of registering for classes is often different from experiences that the international students have had at academic institutions in their country of origin. Students are often not well informed about the curriculum and the credits system of the new university or college. Some students may want to complete their degree requirements early, so they register for many credit hours, which can place additional stress on them. Students may also struggle with choosing a major. While many international students come to the new university or college with a predetermined academic plan, they may want to change their major after they are exposed to different areas of study and new career opportunities.

Students have expectations about the new academic experience once they have registered for classes and are ready to start school. These expectations involve interactions with faculty and other students. The first day in class plays a critical role in a student's adjustment. Normally, this is a time for testing hypotheses about the new academic environment. It is also a time for observation, where the student is learning about self and others in the academic setting. The international student may easily recognize that he or she is different from others in the class in regards to culture and language. If the student has a positive experience on his or her first day, he or she is more likely to feel confident and optimistic about the transition. 
Students continue to adjust to the school system while coping with many other issues. For those who are attending school where courses are taught in a language in which the student is not fluent, language barriers can be another issue associated with academic adjustment. Students have to deal with learning the language while trying to learn as much they can in class. Learning styles such as, auditory, visual, or pragmatic learning can influence the students' ability to comprehend. Some students are from educative systems where rote memory, hands on experience or pragmatics are valued. Young (2011) compared the influence of learning style preferences of first year international students on achievement and anxiety level over one semester. He found that the students' learning style did not alter much during the six-week course, however, they were able to adapt to the new learning environment. Asian students were accustomed to more formal, authoritative lecture. They were oriented toward rote memorization, and they were likely to work alone. The instructors were able to accommodate the individual learning needs by being cognizant of learning style differences. The students then became more comfortable in the new learning environment.

International students often have to adjust to different methods of evaluation. Evaluation time can be particularly stressful for them. Some students are good at writing essays, while others are better at taking multiple choice exams. Those students who are not familiar with the university's methods of evaluation may experience significant anxiety. International students are encouraged to seek guidance from their instructor(s) about test preparation and test taking strategies. They are also encouraged to be patient and flexible while they learn and adjust to different methods of evaluation. Some students experience financial hardships and find it difficult to meet their academic goals. It is important to seek out advice when facing these situations as they have the potential to influence the student's academic progress.

It is normal for students to set high expectations and goals for themselves as they pursue a degree. Some students may experience anxiety because they have set unrealistic expectations and goals. International students can learn from their interaction with domestic students. Some international students place great value on education. However, it is important to be aware that like in any university, some students are unmotivated to learn. International students' experience is unique. Both learning style and environment are important factors in determining the students' academic adjustment. The university or college can help alleviate the students' anxiety by creating an environment where the students are empowered by knowledge and information about the registration, curriculum, and grading systems. Universities and colleges are encouraged 
to assign international students to academic advisors who are culturally sensitive and experienced in working with this population. The first encounter or the first impression that the student has of the university can have a long lasting effect on his or her adjustment. Students can have successful adjustment if they are flexible and open to seeking out advice. Most universities and colleges provide orientation for new students, including international students. This is a golden opportunity for networking and identifying resources such as tutoring, library, and counseling services.

\section{Psychological Adjustment}

Mental health status and other factors (biological, environmental) are predictors of international students' psychological adjustment. The psychological distress experienced by international students is well documented in the literature (Hwang, Bennet, \& Beauchemin, 2014; Wang, et al., 2015; Zhang \& Goodson, 2011). Depression and anxiety are commonly experienced during the process of adjusting to a new environment. Some international students experience loneliness, culture shock, and somatic complaints such as headaches (which are manifestations of psychological symptoms in some cultures). In a review of research on the psychological adjustment of students studying in foreign countries, Church (1982) found that the most common problems experienced by the students during the adjustment process included, language barriers, financial problems, adjustment to the new educational system, homesickness, adjustment to social customs and norms, and racial discrimination. Some international students struggled with depression, anxiety, academic difficulties, relationship issues (Nilsson, Berkel, Flores, \& Lucas 2004; Yi et al., 2003; Yokushko et al., 2008), loneliness, and cultural adjustment (Yokushko et al., 2008) while adjusting to their host country. Li, Wang, and Xiao (2014) conducted a systematic review of 18 studies conducted from 2000 to 2011 that focused on the psychological well-being of East Asian international students. They found that the students' psychological wellbeing was significantly associated with the length of stay in the host country, English proficiency, attitudes toward seeking help, depression, and acculturation. More importantly, depression was the most frequently reported issue, followed by acculturation. Han, Han, Jacobs, and JeanBaptiste (2013) found that approximately $45 \%$ of Chinese international students in their study reported symptoms of depression, and $29 \%$ reported experiencing some symptoms of anxiety. Sa, Seo, Nelson, and Lohrmann (2013) found that levels of acculturative stress, anxiety, and depression were predictors of South Korean international students' smoking prevalence. International students who engaged in self-critical perfectionism were more likely to experience severe depression (Rice, Choi, Zhang, Morero, \& 
Anderson, 2012). Some of the students who internalized their adjustment issues experienced reactive depression and/or anxiety. Reactive or situational depression is a response caused by specific psychosocial stressors. Reactive depression often occurs in response to the international student's experience of loss, moving, and/or acculturation. Students who externalized the issues associated with adjustment exhibited aggressive behaviors. Self-efficacy and perceived social support from friends and significant others were significantly related to international students' positive psychological adjustment (Yusoff, 2012).In addition, Tavakoli, Lumley, Hijazi, Slavin-Spenny, and Parris (2009) found that group assertiveness training helped to improve international students' emotional adjustment.

Individual differences play a critical role in psychological adjustment. Individuals with certain personality types often find it easier to adapt to new situations than others. Personality traits such as extroversion (Eun-Ju, Lu, \& Jeongwoo, 2011; Lin et al., 2012; Ying, 2002), openness to experience and neuroticism (Eun-Ju et al., 2011) were significant predictors of psychological adjustment. Wang et al. (2012) found that higher selfesteem, positive problem-solving skills, and lower maladaptive perfectionism were significant predictors of better acculturative adjustment. Establishing a social support system, and utilizing coping skills, such as acceptance, reframing, and striving were associated with better crosscultural transition. Gender differences were also predictors of psychological adjustment. Lee, Park, and Kim (2009) found significant gender differences in Korean international college students' psychological adjustment. Korean female students had a higher level of psychological adjustment than their male counterparts. However, it is important to note that language proficiency positively predicted adjustment across gender.

Another concept that helps to understand the role of individual differences in psychological adjustment is resilience. Resilience refers to the ability to bounce back following difficult experiences (e.g., adversity, trauma, stress). According to Masten, Best, and Garmezy (1990), "resilience is the process of, capacity for, or outcome of successful adaptation despite challenging or threatening circumstances" (p.426). Resilience is often negatively associated with psychological adjustment problems (Wang, 2004).

Early family and community dynamics also influence psychological adjustment. Positive early experiences are associated with better adjustment outcomes. In this context, family plays an important role in one's ability to adjust to new life situations. Students who have secure attachments with their family or caregiver(s) tend to have a smoother transition in to a new culture. Students who have a secure attachment tend to view the world as a 
safe place; therefore, are more likely to create new social attachments in their host country. The ability to connect with others may help alleviate feelings of isolation, and homesickness. Maintaining good relationships with family, friends, and the community while studying abroad may help during the adjustment process. Expressing one's emotions, challenges, and needs to someone with whom the student feels close can be very cathartic.

Coping style influences psychological adjustment. Folkman and Moskowitz (2004) defined coping as the thoughts and behaviors used to manage the internal and external demands of situations that are appraised as stressful. Students utilize different styles of coping to deal with adjustment issues. Individuals generally engage in what Lazarus and Folkman (1984) called emotional-focused and/or problem-focused coping. The difference between the two types of coping styles lies in the assumption that emotional-focused coping tends to lessen the emotional response associated with the situation while problem-focused coping tends to eliminate or reduce the actual situation causing the distress. Locus of control also effects how the students cope with their stressors. Those who have an internal locus of control may feel more confident to cope with their stressors than those who have an external locus of control, who tend to make external attributions for their problems.

It would be helpful for students, and those who work with them, to be knowledgeable about positive and negative coping styles. The literature suggests that international students are more likely to rely on their spirituality to cope with life stressors than domestic students. Chai, Krägeloh, Shepherd, and Billington (2012) found that Asian international students were more likely than European college students to utilize religious coping and that this style of coping was more efficient for improving their psychological well-being and quality of social life. The international students' use of coping skills such as acceptance, reframing, and striving was associated with better cross-cultural adjustment (Wang \& Heppner, 2012). Higher self-esteem, positive problem-solving appraisal, and lower maladaptive perfectionism prior to the acculturation process significantly predicted acculturative adjustment for Chinese international students (Wang \& Heppner, 2012). Smith and Khawaja (2014) investigated the STAR program: Strengths, transitions, adjustments, and resilience; a psychological intervention aimed at enhancing the coping and adjustment of international college students. Students who participated in the intervention reported significant improvement in psychological adaptation and coping selfefficacy, but no significant improvement in psychological distress. Higher levels of personal and multicultural strengths were predictors of less acculturative problems, thus resulting in better psychological adjustment (Yakunina, Weigold, Weigold, Hercegovac, \& Elsayed, 2013). 


\section{Counseling Utilization}

Some international students are at greater risks for developing psychological distress than others. Counseling may assist the students in coping with adjustment issues. International students' intentions, attitudes, and behaviors toward seeking mental health service are well-documented. The literature suggests that international students underutilized counseling services (Bong Joo, Bennett, \& Beauchemin, 2014). Onabule and Boes (2013) found that some students perceived counseling as a negative term, but described the experience with their academic advisor positively. Some students did not understand the benefits of attending counseling services. Mesidor and Sly (2014) investigated the relationship between socialcognitive factors (e.g., attitudes, subjective norms, and perceived behavioral control), psychological distress, and help-seeking intentions among international and African American college students using Ajzen's (1991) Theory of Planned Behavior. They found that perceived behavior control was the strongest predictor of mental health seeking intentions, suggesting that students' self-efficacy or their perceived ability (available resources) was an important determinant of their intentions to seek mental health services. International students' resistance toward mental health services can best understood by their cultural mistrust toward mental health professionals, stigma associated with mental illness, and lack of resources (health insurance). Several other factors seem to interfere with the students seeking mental health counseling including, language proficiency, culture, and gender.

Universities and colleges need to reach out to international students in order to educate them about the benefits of counseling services (Onabule \& Boes, 2013). Because of the cultural differences among international students, it is critical to hire culturally sensitive counselors to work with them. Mental health professionals working in university counseling centers should be cognizant of problems faced by international students in order to develop some level of comfort and expertise working with this diverse population. Providing therapeutic services that are culturally sensitive and evidenced based can make therapy more efficacious. Being culturally sensitive and recognizing the student as the expert can foster better therapeutic relationships and outcomes.

\section{RECOMMENDATIONS}

Many international students experience cultural, social, psychological, and academic adjustment issues. Thus, it is recommended that the students, university/college, and others involved in student affairs, work on a special 
adjustment plan to facilitate a smooth transition from home to the host country. The host college/university can accomplish this by maintaining a website that contains current and pertinent information for international students. They can also reduce some of the anxiety associated with adjusting to a new environment by sending information about the college, the city, the environment, and the culture to potential students prior to them relocating. Traveling with unrealistic expectations can create disappointment and frustration. Chan (2012) suggested that students “expect the unexpected," by being prepared emotionally and mentally. Make the students feel welcome. This can be accomplished by creating a culture that facilitates adjustment. Invite other international students attending the college/university to be a part of the welcoming activities for the incoming students. In addition, international students already attending the college/university can also be assigned as mentors for incoming students to facilitate the adjustment process. It would be ideal for the universities/colleges and the students to work collaboratively on cultural, academic, and psychological adjustment issues in order to foster a smooth transition.

Like other coping mechanisms, resilience can be cultivated. One way to foster resilience is for the student to develop self-awareness about his or her emotions, strengths, and limitations. Encourage the students to observe other resilient people; interact with positive people; and develop mantras or positive affirmations that would help to transcend negative thoughts and experiences. Resilient people are those who learn from their mistakes by regarding them more as challenges than failures. Importantly, being in the present moment through mindfulness exercises can enhance resilience. Owen and Kalavala (2012) indicated how mindfulness and yoga techniques have been helpful in relieving stress in high school students.

It is critical to understand the culture in which one plans to become a member. People who are strongly attached to their own culture find it more difficult to learn and adapt to the mores, customs, and the language of a novel culture. While they are encouraged to keep in touch with family and friends in their own culture, international students need to learn about the new culture in which they are living. This can be accomplished through the media (reading newspapers, watching television and listening to the radio) and interacting with local people.

Most employers will not hire international students due to their immigration status. Universities/colleges are encouraged to assist international students in solving some of their financial issues. This can be achieved by creating job opportunities within the university/college settings where the students can work. Working provides a sense of meaning for international students. Meaningful work can help in the adjustment process. 
To meet the academic needs of international students, both the university/college and students should collaborate on an educational plan that addresses relevant academic issues (degree plan, curriculum, academic challenges). Each student needs an assigned academic adviser and a mentor who will provide support throughout the academic year. In order to overcome language challenges, Kuo (2011) suggested that international students should get training in listening comprehension or learn about the accent that people speak in the US or the regions where they plan to study before coming to the United States. He encouraged, where available, the students to enroll in classes taught by American professors while in their home country. They could also seek out employment or involvement in American companies, schools, or churches. Young (2011) suggested that students work toward improving their English by focusing on oral communication skills rather than focusing on reading and written English language.

Importantly, students' self-efficacy, which is their belief in their ability to succeed, can influence their interaction with others, and their academic performance. Telbis, Helgeson, and Kingbury (2014) found that students who scored high on a measure of self-efficacy or confidence levels in completing their programs of study also had high scores on their confidence in their resources. Those who had low scores in confidence for completing their programs of study also scored low on their confidence in coping with social adaptation, language barriers, academic ability, and financial difficulty issues. Edwards-Joseph and Baker (2014) found that educational background, faith in God, finances, age and maturity, influence and support of others, self-determination, and previous success of others and self were contributive factors of international students' academic selfefficacy. Thus, it is essential that those who work directly with international students stress the importance of recognizing their strengths. Professors and instructors should be cognizant of their role as academic role models and how their teaching and interaction with international students can shape their worldview and their ability to succeed in life. Professors' expectations of their students are predictors of whether the student will succeed or fail. This is referred to as the Pygmalion Effect (Rosenthal \& Jacobsen, 1968). Positive expectations can influence positive performance, and negative expectation can influence performance negatively. Regardless of the language barriers, if a professor has a greater expectation of a student, he or she will perform to the fullest potential.

International students are likely to face adjustment issues in several areas. In order to lessen the anxiety and stress experienced by these students, future research should focus on the self-care of international students. Selfcare, time management, and stress management are also critical in 
understanding adjustment. As stated above, international students may experience significant stress as they attempt to manage the demands of studying and living abroad. Balancing the demands of schoolwork and acculturation would make life easier, healthier, and more productive. Selfcare involves getting enough sleep, exercising, eating a healthy balanced diet, going out with friends, taking breaks, and traveling when it is affordable. Sleeping is very important because it helps consolidate memory and learning, and improve mood. Burkhart (2014) proposed a model of selfcare for graduate psychology students. An emerging theme was building consciousness (defined as the development of awareness, balance, connection, flexibility, inclusivity, and perspective).

Students, educators, and all those involved with international students should be aware that some cultures are more time oriented than others. In some cultures, it is required to be on time. Paton (2007) found time management was among the factors that contributed to the academic failure of international students. Thus, time management is a necessary skill. Students are encouraged to plan their activities so that they can become more effective, efficient, and productive. It is essential to set priorities when there are many tasks to accomplish. Meeting school assignment and other school related activities' deadlines are important milestones toward completing a college degree. On the other hand, procrastination is the enemy of academic progress and success. Students may feel more relaxed, easy going, and productive when they manage their time appropriately. Students are encouraged to practice time management as it may help reduce the stresses or anxiety associated with school and acculturation. Overall, selfcare and effective time management are contributing factors to stress management. Some stress management techniques include mindfulness, exercise, diaphragmatic breathing exercises, meditation, guided imagery, etc. These techniques have the potential to empower the mind and body. This illustrates the Latin saying "mens sana in corpore sano" (a healthy mind in a healthy body).

An understanding of the acculturative stress experienced by international students can help academic institutions provide better services to support these students. College and university faculty can create culturally sensitive programs to help normalize the adjustment process by bringing in senior and alumni international students to share their adjustment experiences (Nasirudeen, Koh, Lau, Seng, \& Ling, 2014). Similarly, Abe Talbot and Geelhoed (1998) found that international students who participated in international peer programs showed significant social adjustment. 


\section{CONCLUSION}

Adjustment is a multidimensional process that involves several factors. The purpose of this article is to address factors contributing to the cultural, social, academic, and psychological adjustment of international students. International students' early life experiences, resilience, self-efficacy, spiritual, social support, coping style, personality, emotional and cultural intelligence are important components of the adjustment process. Adjustment is a unique process and each student may experience associated issues differently. No single factor determines healthy or unhealthy/maladaptive adjustment. The students who experience psychological distress are not less intelligent than those who successfully adapt to their new environment. This article highlights how the interaction between different factors affects adjustment. While adjustment issues are common among international students, the literature consistently indicates that they underutilize mental health services. Research suggests that cultural mistrust, stigma associated with mental illnesses, and lack of resources (health insurance, financial strain) are contributing factors to international students' mental health help-seeking behaviors.

Whereas some students may experience acculturative stress, psychological distress, and academic difficulties, protective factors such as their coping styles, including social support, resilience, and spirituality can alleviate the stress associated with the experience of living and learning in a new culture. Universities and colleges are encouraged to integrate services or create an international program within the university that promotes wellness and that makes the transition less stressful. The students are encouraged to take advantage of programs offered by their university such as counseling services, mentorship, tutoring, and other culturally sensitive activities that promote a seamless transition. It is important that those who work with international students are cognizant of their own cultural bias. An awareness of their own bias can help to identify their limitations. Knowing ones limitations can provide some insights into what can be improved; thus, promoting areas of growth and cultural sensitivity. Likewise, students are encouraged to be flexible in their approach to interacting, learning, and acculturating in their new environment. Flexibility in coping is a hallmark of adjustment and adaptation, which is a lifelong learning process. This article suggests that students are better served when the academic institutions are knowledgeable about factors that contribute to the adjustment process such as, how to recognize the symptoms of maladaptive adjustment, healthy or unhealthy coping styles, and services needed to promote cultural, academic, and psychological well-being. Providing a well-rounded education to an international student population can be at times challenging; however, one 
must keep in mind that it can also be very rewarding. Knowledge is a powerful and transformative tool for ameliorating human condition. By providing education for international students, colleges and universities are preparing the future world leaders and those who are going to make a difference in the lives of their fellow citizens.

\section{REFERENCES}

Abe, J., Talbot, D. M., \& Geelhoed, R. J. (1998). Effects of a peer program on international student adjustment. Journal of College Student Development, 39, 539-547.

Ajzen, I. (1991). The theory of planned behavior. Organizational Behavior and Human Decision Process, 50, 179-211.

Baba Y., \& Hosoda, M. (2014). Home away home: Better understanding of the role of social support in predicting cross-cultural adjustment among international students. College Student Journal, 48(1), 1-15.

Bong Joo, H., Bennett, R., \& Beauchemin, J. (2014). International students' utilization of counseling services. College Student Journal, 48(3), 347-354.

Burkhart, J. (2014). An integrated model of self-care for clinical psychology graduate students. Journal of Integral Theory \& Practice, 9(1), 5573.

Chai, P. M., Krägeloh, C. U., Shepherd,D., \& Billington, R. (2012). Stress and quality of life in international and domestic university students: cultural differences in the use of religious coping. Mental Health, Religion \& Culture, 15(3), 265-277. doi:10.1080/13674676.2011.571665.

Chan, H., Y. (2012). My journey as an international doctoral student in the United States. Journal of International Students, 2(2), 133-134.

Chavajay, P. (2013). Perceived social support among international students at a U.S. university. Psychological Reports, 112(2), 667-677. doi:10.2466/17.21.PR0.112.2.667-677.

Church, A. T. (1982). Sojourner adjustment. Psychological Bulletin, 9, 540572.

Duru, E., \& Poyrazli, S. (2011). Perceived discrimination, social connectedness, and other predictors of adjustment difficulties among Turkish international students. International Journal of Psychology, 46(6), 446-454.

Edwards-Joseph, A., \& Baker, S. (2014). Factors Caribbean overseas students perceive influence their academic self-efficacy. Journal of International Students, 4(1), 48-59. 
Eun-Ju, L., Lu, L., \& Jeongwoo, J. (2011). Internet for the internationals: Effects of internet use motivations on international students' college adjustment. Cyberpsychology, Behavior \& Social Networking, 14(7/8), 433-437. doi:10.1089/cyber.2010.0406.

Folkman, S., \& Moskowitz, J. (2004). Coping: Pitfalls and promise. Annual Review of Psychology, 55(1), 745-774. doi:10.1146/annurev.psych.55.090902.141456

Gebhard, J., G. (2012). International Students' Adjustment Problems and Behaviors. Journal of International Students, 2(2), 184-193.

Gómez, E., Urzúa, A., \& Glass, C. R. (2014). International student adjustment to college: Social networks, acculturation, and leisure. Journal of Park and Recreation Administration, 32(1), 7-25.

Gullekson, N. L., \& Tucker, M. L. (2012). An examination of the relationship between emotional intelligence and intercultural growth for students studying abroad. Journal of the Academy of Business Education, 13, 162-178.

Han, X., Han, X., Luo, Q., Jacobs, S., \& Jean-Baptiste, M. (2013). Report of a mental health survey among Chinese international students at Yale University. Journal of American College Health, 61(1), 1-8.

Harrison, J. K., \& Brower, H. H. (2011). The impact of cultural intelligence and psychological hardiness on homesickness among study abroad students. Frontiers: The Interdisciplinary Journal of Study Abroad, 21, 41-62.

Hwang, B.J., Bennett, R., \& Beauchemin, J. (2014). International students' utilization of counseling services. College Student Journal, 48 (3), 347-354.

Institute of International Education, Open Doors (IIE) (2014). International student enrollment in the U.S. Retrieved from http://www.iie.org. International students. International Journal of Intercultural Relations, 35, 699-

International students. Journal of Instructional Psychology 30 (4), 333-342.

Jazaeri, S. A., \& Kumar, S. K. (2008). Emotional intelligence and cultural adjustment among foreign students in India. Psychological Studies, 53(1), 83-89.

Ji-yeon, L., \& Pistole, M. C. (2014). International student sociocultural adaptation: gossip and place attachment contributions. Journal of Mental Health Counseling, 36(4), 345-359.

Kuo, Y-H. (2001). Language Challenges Faced by International Graduate Students in the United States. Journal of International Students, 1 (2), 38-42. 
Lazarus, R. S., \& Folkman, S. (1984). Stress, appraisal, and coping. New York: Springer.

Lee, S. A., Park, H. S., \& Kim, W. (2009). Gender differences in international students' adjustment. College Student Journal, 43(4), 1217-1227.

Li, J., Wang, Y., \& Xiao, X. (2014). East Asian International Students and Psychological Wellbeing: A Systematic Review. Journal of International Students, 4 (4), 301-313.

Lin, J., Peng, W., Kim, M., Kim, S. Y., \& LaRose, R. (2012). Social networking and adjustments among international students. New Media \& Society, 14(3), 421-440. doi:10.1177/146144481141862.

Lowinger, R., He Z., Lin, M., \& Ghang, M (2014). The impact of academic self-efficacy, acculturation difficulties, and language abilities on procrastination behavior in Chinese international students. College Student Journal, 48 (1), 141-152.

Masten, A. S., Best, K. M., \& Garmezy, N. (1990). Resilience and development: Contributions from the study of children who overcome adversity. Development and Psychopathology, 2(4), 425444. doi:10.1017/S0954579400005812.

Mesidor, J. K., Sly, K. F. (2014). Mental health help-seeking intentions among international and African American college students: An application of the theory of planned behavior. Journal of International Students, 4(2), 137-149.

Mohd-Yusoff, Y., \& Othman, A. K. (2011). An early study on perceived social support and psychological adjustment among international students: The case of a higher learning institution in Malaysia. International Journal of Business \& Society, 12(2), 1-15.

Morrell, D., Ravlin, L., Ramsey, J. R., Ward, A. K. (2013). Past Experience, Cultural Intelligence, and Satisfaction with International Business Studies. Journal of Teaching in International Business. 24 (1).

Nasirudeen, A. M., Koh, W. N. J., Lau, L., L. C. A., Seng, L. L., \& Ling, A. (2014). Acculturative stress among Asian international students in Singapore. Journal of International Students, 4(4), 363-373.

Nilsson, J. E., Berkel, L. A., Flores, L. Y., \& Lucas, M. S. (2004). Utilization rate and presenting concerns of international students at a university counseling center: Implications for outreach programming. Journal of College Student Psychotherapy, 19, 49-59.

Onabule, A. I., \& Boes, S., R. (2013) International students' likelihood to seek counseling while studying abroad. Journal of International Students, 3(1), 52-59. 
Owen, J. \& Kalavala, P. (2012). Multicultural expedition into mindfulness among high school students. Journal of International Students, 2(1), 85-86.

Parker, R. S., Pettijohn, C. E., \& Rozell, E. J. (2011). Emotional intelligence: International students and the business school curriculum. Global Education Journal, (4), 123-146.

Paton, M. J. (2007). Why international students are at greater risk of failure: An inconvenient truth. International Journal of Diversity in Organisations, Communities \& Nations, 6(6), 101-111.

Poyrazli, S. \& Grahame, K. (2007). Barriers to adjustment: Needs of international students within a semi-urban campus community. Journal of Instructional Psychology, 34, 28-45.

Rawlings, M. S. \& Sue, E. (2013). Preparedness of Chinese students for American culture and communicating in English. Journal of International Students, 3(1), 29-40.

Rice, K. G., Choi, C., Zhang, Y., Morero, Y. I., \& Anderson, D. (2012). Self-critical perfectionism, acculturative stress, and depression among international students. Counseling Psychologist, 40(4), 575600.

Rienties, B., Beausaert, S., Grohnert, T., Niemantsverdriet, S., \& Kommers, P. (2012). Understanding academic performance of international students: The role of ethnicity, academic and social integration. Higher Education, 63(6). 685 - 700.

Rosenthal, R, \& Jacobsen, L. (1968). Pygmalion in the classroom: teacher expectation and pupils' intellectual development. New York: Holt, Rinehart and Winston.

Sa, J., Seo, D., Nelson, T. F., \& Lohrmann, D. K. (2013). Cigarette smoking among Korean international college students in the United States. Journal of American College Health, 61(8), 454-467.

Smith, R. A. \& Khawaja, N. G. (2011). A review of the acculturation experiences of international students. International Journal of Intercultural Relations, 35, 699-713.

Smith, R. A., \& Khawaja, N. G. (2014). A group psychological intervention to enhance the coping and acculturation of international students. Advances in Mental Health, 12(2), 110-124. doi:10.5172/jamh.2014.12.2.110.

Tavakoli, S., Lumley, M. A., Hijazi, A. M., Slavin-Spenny, O. M., \& Parris, G. P. (2009). Effects of assertiveness training and expressive writing on acculturative stress in international students: A randomized trial. Journal of Counseling Psychology, 56(4), 590596. doi:10.1037/a0016634. 
Telbis, N. M., Helgeson, L., \& Kingsbury, C., (2013). International students' confidence and academic success. Journal of International Students, 1(2), 43- 49.

Trifonovitch, G. J. (1977). Culture learning/culture teaching. Educational Perspectives, 16(4), 18-22.

Wang, J. (2004). Using resilience characteristics and traditional background factors to study adjustment of international graduate students in U.S. Online Submission.

Wang, K. T., \& Heppner, P. P. (2012). Profiles of acculturative adjustment patterns among Chinese international students. Journal of Counseling Psychology, 59(3), 424-436. doi:10.1037/a0028532.

Wang, K. T., Heppner, P. P., Fu, C., Zhao, R., Li, F., \& Chuang, C. (2012). Profiles of acculturative adjustment patterns among Chinese international students. Journal of Counseling Psychology, 59(3), 424-436. doi:10.1037/a0028532.

Wang, K.T, Wei, M., Zhoa, R., Chuang, C. \& Li, F. (2015). The crosscultural loss: Development and psychometric evaluation. Psychological Assessment, 27(1), 42-53.

Wei, M. Heppner, P., Mallen, M., Ku, T., Liao, K. \& Wu, T (2007). Acculturative stress, perfectionism, years in the United States, and depression among Chinese international students. Journal of Counseling Psychology, 54, 385-394.

Yakunina, E. S., Weigold, I. K., Weigold, A., Hercegovac, S., \& Elsayed, N. (2013). International students' personal and multicultural strengths: Reducing acculturative stress and promoting adjustment. Journal of Counseling \& Development, 91(2), 216-223. doi:10.1002/j.15566676.2013.00088.x

Yakushko, O., Davidson, M., \& Sanford-Martens, T. C. (2008). Seeking help in a foreign land: International students' use patterns for a U.S. university counseling center. Journal of College Counseling, 11(1), 6-18.

Yi, J. K., Lin, J. C. G., \& Kishimoto, Y. (2003). Utilization of counseling services by international students. Journal of Instructional Psychology, 30(4), 333-342.

Ying, Y. (2002). Formation of cross-cultural relationships of Taiwanese international students in the United States. Journal of Community Psychology, 30(1), 45-55.

Young, A. S. (2011). First time international college students' level of anxiety in relationship to awareness of their learning-style preferences. Journal of International Students, 1(2), 43-49.

Yusoff, Y. M. (2012). Self-efficacy, perceived social support, and psychological adjustment in international undergraduate students in 
a public higher education institution in Malaysia. Journal of Studies in International Education, 16(4), 353-371. doi:10.1177/1028315311408914.

Zhang, J., \& Goodson, P. (2011). Predictors of international students' psychosocial adjustment to life in the United States: A systematic review. International Journal of Intercultural Relations 35(2), 139162.

JEAN KESNOLD MESIDOR, PH.D, is a Postdoctoral Fellow in Clinical Health Psychology at Florida State University College of Medicine, Immokalee Health Education Site. He received his Ph.D. in Clinical Psychology from Jackson State University, MS. His areas of interest include trauma, toxic stress, posttraumatic growth, weight management, and mental health seeking intention and behavior in multicultural populations. E-mail: mesidorjeank@gmail.com

KAYE F. SLY, PH.D, is an Associate Professor in the Psychology Department at Jackson State University (JSU), Mississippi. She received her Ph.D. in Clinical Psychology at the Southern Illinois University-Carbondale. She is a clinical psychologist and is the Director of the Community Health Program at JSU. Her areas of interest include: HIV/STD prevention service and research, women's health disparities, substance abuse treatment and prevention and dual diagnosis. 